Karina Sami Yamamoto Inoue ${ }^{1}$

Rodolfo Andrade de Gouveia Vilela ${ }^{2}$

\title{
O poder de agir dos Técnicos de Segurança do Trabalho: conflitos e limitações
}

\author{
Occupational safety and health technicians' power of action: \\ conflicts and limitations
}

\section{Resumo}

Objetivo: conhecer as vivências dos Técnicos de Segurança do Trabalho no desenvolvimento de suas atribuições nas empresas, bem como suas percepções sobre os reflexos do exercício profissional sobre a sua saúde. Métodos: pesquisa qualitativa com uso da técnica da Análise Coletiva do Trabalho, na qual trabalhadores em grupo abordam os aspectos materiais e subjetivos de seu fazer, e posterior análise de conteúdo dos relatos dos participantes. Resultados e discussão: na percepção dos Técnicos seu trabalho é caracterizado por limitações constantes no exercício de suas atividades e por conflitos com os diferentes níveis hierárquicos das empresas. O desvio de função foi apontado como prática corrente, com destaque para atividades administrativas e vigilância patrimonial. Os aspectos identificados como determinantes dessa situação foram: priorização, pelas empresas, da produção em detrimento da prevenção; inserção frágil do Técnico na política de segurança das empresas; atuação conflituosa por sua posição intermediária entre trabalhadores e gestores; ausência de proteção contra despedida desmotivada; predominância da abordagem comportamental de segurança nas empresas e entre os próprios Técnicos. Essas limitações e constrangimentos foram apontados como prejudiciais ao desenvolvimento de ações preventivas e como causa de sofrimento mental e adoecimento desses trabalhadores.

Palavras-chave: técnico de segurança do trabalho; sofrimento no trabalho; ergonomia da atividade.

\begin{abstract}
Objective: to study Occupational Safety and Health Technicians' experiences in developing preventive activities, as well as their awareness on the reflexes of their occupational practice on their own health. Methods: qualitative research, using the Collective Work Analysis technique, in which Technicians in group address the material and subjective aspects of their work, followed by content analysis of the participants' reports. Results and discussion: the Technicians are aware that their work is characterized by constant limitations in their daily practices and by conflicts with different hierarchical levels within the companies. Function deviation was appointed as a current practice, especially among managerial activities and property surveillance. The determining aspects to this working condition are as follows: The enterprise's prioritization of production to the detriment of prevention; Technicians' fragile insertion in the companies' safety policies; continuous conflicts due to Technicians' intermediate position between workers and managerial level; absence of protection against unmotivated dismissal; prevalence in companies and among technicians of behavioral approach to security. These limitations and constraints were pointed as harmful to the development of preventive actions and as the cause of mental suffering and diseases among these technicians.
\end{abstract}

Keywords: occupational safety and health technician; suffering at work; activitycentered ergonomics. 


\section{Introdução}

No âmbito das empresas, a responsabilidade pela preservação da saúde e a garantia da segurança dos trabalhadores cabe ao Serviço Especializado em Engenharia de Segurança e Medicina do Trabalho (SESMT). O Serviço é regulado por normas estatais que se aplicam aos trabalhadores formais cujo regime de trabalho é regido pela Consolidação de Leis do Trabalho (BRASIL, 1943)

O Serviço tem por objetivo maior a prevenção de acidentes de trabalho e de doenças ocupacionais e, para tanto, os profissionais de saúde e segurança do trabalho devem lançar mão de uma série de iniciativas para o desenvolvimento de ações preventivas. A legislação trabalhista vigente define como atribuições principais desses profissionais reduzir até eliminar os riscos existentes no ambiente de trabalho e, não sendo possível, determinar o uso de equipamentos de proteção coletiva ou o uso de Equipamentos de Proteção Individual (EPI) pelo trabalhador. O SESMT também deve colaborar no projeto e implantação de novas instalações da empresa, responsabilizar-se pelo cumprimento das Normas Regulamentadoras (NR) aplicáveis àquela empresa, promover atividades educativas para os trabalhadores, registrar e analisar acidentes e incidentes ocorridos (BRASIL, 1978, 1983).

O dimensionamento do SESMT varia de acordo com o porte da empresa - número de trabalhadores que possua e o grau de risco oferecido pela atividade desenvolvida. A composição da equipe do SESMT pode variar, mas Técnico de Segurança do Trabalho é a categoria que sempre se faz presente. A equipe completa do SESMT pode ser composta ainda por médico e enfermeiro do trabalho, auxiliar de enfermagem, engenheiro de segurança do trabalho (BRASIL, 1978, 1987).

O setor metalúrgico é um ramo que oferece elevado grau de risco aos trabalhadores. Dessa forma, a legislação trabalhista brasileira determina a implantação e manutenção de SESMT em todas as empresas metalúrgicas que possuam a partir de 50 trabalhadores. Portanto, é possível afirmar que o Técnico de Segurança do Trabalho é o profissional de saúde e segurança presente em grande parte das empresas metalúrgicas. Entretanto, em levantamento bibliográfico realizado foram encontrados poucos estudos a respeito do trabalho desses profissionais de saúde e segurança.

Salazar et al. (2003) aplicaram questionário a profissionais de serviço de saúde ocupacional de dez estabelecimentos de armazenamento de armas nucleares norte-americanos, constatando problemas de comunicação nos serviços e divergência entre os riscos físicos identificados nos estabelecimentos pelos profissionais e as ações protetivas oferecidas. Takaro et al. (2000) investigaram a percepção dos profissionais sobre melhoria na qualidade do serviço após mudança em procedimentos internos. Van Der Drift (2002) identificou a necessidade de melhor qualificação dos profissionais de saúde e segurança das empresas.

Na realidade brasileira, Cavalheiro et al. (2011) pesquisaram o SESMT de empresa moveleira, identificando as tarefas de responsabilidade de seus membros. Pesquisando a ocorrência de quase-acidentes em empresa de construção civil, Cambraia, Formoso e Saurin (2008) descreveram as tarefas executadas pelo Técnico de Segurança de Trabalho para a prevenção desse tipo de evento. No mesmo ramo, Fonseca e Lima (2007) estudaram análises de acidentes de trabalho realizadas por Técnico de Segurança e as propostas preventivas derivadas de suas conclusões.

Na maior parte das pesquisas identificadas há apenas a menção ao profissional como parte do quadro de profissionais do SESMT, havendo em número mais reduzido de estudos onde há a referência ao Técnico de Segurança como participante em uma atividade pontual (ginástica laboral, treinamento da brigada de incêndio etc.).

Temos no país quase 300 mil Técnicos de Segurança do Trabalho ativos (FEDERAÇÃO NACIONAL DOS TÉCNICOS DE SEGURANÇA DO TRABALHO, 2012). Ainda que em números absolutos a categoria profissional no país não constitua volume significativo, ela tem potencial de contribuir para a prevenção de doenças e acidentes com trabalhadores de indústrias de importância crucial para a economia e o desenvolvimento do país. O Técnico de Segurança do Trabalho tem por atribuição específica identificar, avaliar e informar riscos presentes nos processos de trabalho. O profissional trabalha de forma articulada aos demais integrantes do SESMT para a elaboração e execução de medidas de proteção à saúde dos trabalhadores (BRASIL, 1985, 1986, 1989, 2008). Assim sendo, as condições de trabalho e a sua configuram-se como assunto relevante para a saúde pública, seja pelo impacto de sua atividade nas ações preventivas, seja pela necessidade de se entender como o trabalho repercute diretamente na saúde desses profissionais.

Cabem alguns esclarecimentos com relação à base conceitual sobre a qual nos embasamos para realizar a discussão dos resultados obtidos com o presente estudo. Ao nos referirmos à "atividade" e "tarefa" o fazemos dentro da conceituação da ergonomia da atividade. Nessa, "tarefa" diz respeito ao que é prescrito ao trabalhador, o que se espera que seja por ele executado; por outro lado "atividade" se refere ao que verdadeiramente é realizado (ASSUNÇÃO; LIMA, 2003). 
Considerando-se o objeto do presente trabalho, justifica-se ainda tratarmos do conceito "nocividade", conforme nos apresentam Assunção e Lima (2003). Tal conceito transcende o olhar da higiene ocupacional que enfoca os agentes físicos, químicos e biológicos presentes nos ambientes de trabalho - a partir do qual se define o trabalho como sendo perigoso ou de risco à saúde. Uma abordagem sistêmica do trabalho implica entender os riscos na complexidade das suas múltiplas interações com os indivíduos e não como decorrentes de fatores isolados. Segundo os autores, a nocividade do trabalho envolve a forma como o trabalhador vivencia uma organização de trabalho rígida, os constrangimentos existentes devido a uma margem de ação reduzida (ASSUNÇÃO; LIMA, 2003).

Convém ainda acrescentar o contraponto com o que Clot denomina "real da atividade", que compreende não apenas o que é executado pelo trabalhador, mas também os impedimentos e dificuldades existentes no contexto de trabalho que limitam a concretização do que lhe é previamente determinado, conceito que contribui para a explicação da relação trabalho e saúde mental (CLOT, 2007). O autor define como real da atividade aquilo que não se faz, aquilo que não se pode fazer (os impedimentos); aquilo que se busca fazer sem conseguir (os fracassos); aquilo que se teria querido ou podido fazer e aquilo que se pensa ou que se sonha poder fazer (os desejos); aquilo que se faz para não fazer (as regulações); aquilo que se faz sem se querer fazer (as imposições); aquilo que se tem de desfazer ou aquilo que se tem de refazer (o retrabalho).

Dessa forma, o comportamento ou a atividade, aquilo que é feito, nada é mais do que "um conjunto de reações que venceram”. A atividade, para o autor, é uma prova subjetiva na qual cada um enfrenta a si mesmo e aos outros para ter uma oportunidade de conseguir realizar aquilo que se tem a fazer. As atividades suspensas, contrariadas ou impedidas, e mesmo as contra-atividades, devem ser admitidas na análise, ou seja, a atividade afastada, ocultada ou inibida nem por isso está ausente. "Pretender prescindir disso na análise do trabalho equivale a retirar artificialmente aqueles que trabalham dos conflitos vitais de que eles buscam libertar-se no real." (CLOT, 2007, p. 116)

A demanda para a realização da atual pesquisa partiu da Gerência Regional de Osasco (SP) do Ministério do Trabalho e Emprego. Estava em andamento no órgão a verificação da adequação de maquinário de empresas metalúrgicas à nova redação da Norma Regulamentadora 12 (Segurança na operação de máquinas e equipamentos), em especial no tocante ao gerenciamento de riscos com máquinas e equipamentos (BRASIL, 2010). Nesse contexto, havia a percepção por parte de auditores fiscais que, mesmo em empresas com política definida e estruturada de gestão de saúde e segurança do trabalho, os profissionais do SESMT possuíam atuação limitada para efetivamente implantar melhorias nas condições de trabalho.

O objetivo do presente artigo é apresentar o conteúdo de trabalho dos Técnicos de Segurança do Trabalho através de suas representações sobre a sua atuação profissional e compreender as dificuldades vivenciadas e os impactos do exercício profissional sobre a sua saúde.

\section{Metodologia}

Foi realizada pesquisa qualitativa, tendo sido utilizada a técnica da Análise Coletiva do Trabalho - ACT (FERREIRA, 1993), que consiste em reunião de grupo de trabalhadores de uma mesma categoria para apresentar sua atividade profissional a dois pesquisadores. A investigação ocorre a partir de pergunta norteadora, no caso, "Como é o trabalho do Técnico de Segurança?”. Os participantes falam e discutem sobre o conteúdo de seu trabalho, tanto em seu aspecto concreto (procedimentos, equipamentos, rotina diária) como em seu conteúdo subjetivo (relações de trabalho, estratégias, regras não escritas). Nesse contexto, a realização com grupo homogêneo (mesma categoria e nível hierárquico) permite não apenas o enriquecimento do conteúdo trazido, através da retroalimentação da discussão entre os participantes, em torno dos temas, como também a confrontação de ideias e opiniões. Vale lembrar que o intuito de compreender o trabalho do ponto de vista dos trabalhadores não significa a busca por uma verdade única, uniforme, da percepção dos elementos do trabalho pelos participantes. Na ACT não apenas cabe, mas mais que isso, promove-se espaço para as diferenças e disparidades de experiências em entendimentos (FERREIRA, 1993).

É preconizado pelo método que as reuniões com os grupos devem ter duração aproximada de 90 minutos, na forma de encontros sucessivos até a saturação, ou seja, até que fiquem esclarecidos para os pesquisadores, minuciosamente, os conteúdos do trabalho, as estratégias utilizadas, as dificuldades e sucessos encontrados na realização do trabalho. Havendo o consentimento de todos os participantes, as reuniões são gravadas, utilizando-se apenas o áudio. Esse material é posteriormente transcrito, havendo leitura e escuta exaustivas para o estabelecimento de categorias empíricas, a partir dos temas mais discutidos pelos trabalhadores e de elementos mais relevantes que compõem a atividade realizada. Fazse necessário que os pesquisadores tenham domínio dos conceitos centrais da ergonomia da atividade (FERREIRA, 1993, 1998, 2011). 
Foram realizados três grupos distintos, que envolveram, no total, 17 Técnicos de Segurança do Trabalho. Para a ACT existe a preocupação de que os trabalhadores participantes sejam voluntários e busca-se também preservar sua identidade, no intuito de evitar a identificação dos sujeitos pelas empresas contratantes, da qual poderiam derivar constrangimentos desses junto aos demais atores no interior das empresas. Os encontros para realização da ACT foram realizados em local externo às empresas. Nos meses de agosto, setembro e outubro de 2011 foram realizados eventos pelo Ministério do Trabalho e Emprego direcionados aos profissionais de saúde e segurança de metalúrgicas dos municípios da região Oeste da Região Metropolitana de São Paulo. Esses tinham por finalidade trazer esclarecimentos a respeito das alterações na Norma Regulamentadora 12 (NR12) no que tange a aspectos de risco de acidentes com máquinas e equipamentos. No encerramento do evento apresentaram-se o projeto de pesquisa e o convite aos técnicos de segurança presentes.

Faz-se necessário ainda pontuar que, para o presente estudo, foi feito recorte no universo de metalúrgicas da região, optando-se por selecionar empresas de médio e grande porte que, por obrigatoriedade legal (BRASIL, 1978, 1987), contam com equipe multiprofissional de segurança (Técnico de Segurança do Trabalho, Médico e Engenheiro do Trabalho), condição que agregaria elementos - positivos ou negativos - à organização do trabalho do Técnico, sendo uma característica importante a ser considerada.

Esta pesquisa foi aprovada pelo Comitê de Ética em Pesquisa (COEP) da Faculdade de Saúde Pública da Universidade de São Paulo (FSP/ USP), sob o protocolo n⿳. 2234, bem como pela Comissão Nacional de Ética em Pesquisa (CONEP) do Ministério da Saúde, protocolo FR405596. Para melhor assegurar a confidencialidade e diminuir possíveis constrangimentos utilizou-se do Termo de Responsabilidade. Esse Termo assegura os esclarecimentos éticos mediante a presença de testemunha, em substituição ao uso do Termo de Consentimento Livre e Esclarecido, sendo dispensada dessa forma a identificação, número de documento de identidade e assinatura do sujeito de pesquisa.

\section{Resultados}

Os Técnicos de Segurança do Trabalho (TST) que realizaram a ACT possuiam tempo de formação e de atuação variada, de dois a mais de 20 anos. Ao longo dos grupos, foi possível observar que os participantes tinham experiência em diversos ramos de atividade econômica.
Durante os três grupos de Análise Coletiva do Trabalho, os Técnicos participantes trouxeram elementos similares e outros díspares. As semelhanças se deram especialmente quanto ao entendimento das atribuições da categoria, de acordo com o definido pela legislação trabalhista, nas descrições das rotinas de trabalho - atividades realizadas frequentemente, protocolos e procedimentos obrigatórios a serem seguidos - e quanto ao trabalho habitual. As diferenças entre os participantes se apresentaram dentro de temas específicos, como, por exemplo, a relação com agentes de fiscalização e a relação com outros atores dentro da empresa. Os conteúdos relevantes para a discussão sobre os conteúdos do trabalho dos TST serão abordados a seguir.

Para a apresentação das falas dos participantes optou-se pela uniformização na forma da sigla TST seguida da numeração dos sujeitos em ordem sequencial; dessa forma é possível relacionar as verbalizações de um mesmo participante sobre os diferentes temas abordados.

\section{A atividade dos Técnicos de Segurança}

Ao longo dos relatos, no momento em que os TST introduziam discussão acerca das dificuldades e limitações encontradas para o cumprimento de suas obrigações, surgiu contraposição entre as determinações legais e as prescrições das empresas contratantes.

A expressão da impossibilidade de realização de suas atribuições pode se dar de maneira clara e aberta:

TST1: Tem empresas em que o profissional nem sala tem. Tem empresa em que o profissional tem sala, mas é proibido de entrar na sala durante o dia.

A falta de estrutura material fornecida ao SESMT também foi apresentada como comum entre os participantes:

TST1: Tem empresas que você chega pra trabalhar e te colocam numa salinha, digitando num computador meia boca, deixa uma luzinha ali: "Olha, isso daqui é a sua sala”. Pingando alguma coisa, faltando outra aqui.

TST2: Embaixo da escada.

TST1: Embaixo do almoxarifado.

Na maior parte das empresas o SESMT está vinculado a um setor com o poder rebaixado. É raro o Serviço responder diretamente a uma instância decisória.

TST4: Geralmente muita coisa é jogada no nosso colo. Para ter uma ideia, eu conheci um Técnico de Segurança que tinha que lavar o carro do patrão uma vez por semana. Lavar. Ele que lavava. O Técnico de Segurança. É incrível. Eu conheço uns que trabalham no RH fazendo folhas de pagamento diariamente. 
TST5: Por exemplo: Eu meço pressão, eu tiro licença da Polícia Federal, Civil, da prefeitura. Eu não tenho que tirar licença, quem tem que tirar é a contabilidade. Até é o [meu] caso: eu estou envolvido com o meio ambiente. Mas eu levo pessoa para o hospital, eu meço pressão, até plaquinha de nome de setor eu tenho que fazer.

TST2: O camarada recebe atribuições como cuidar da segurança patrimonial, cuidar de restaurante, cuidar de frota de veículo, cuidar de máquina de Xerox.

TST5: Vinte por cento de segurança e 80 por cento cuidar de limpeza e jardinagem. [...] E a empresa tinha também canil, porque os cachorros cuidavam da segurança patrimonial. Então eu também tinha que dar um apoio ali na parte do canil com relação a monitoramento, saúde dos cães etc.

Na percepção dos Técnicos, o setor ao qual o SESMT responde explica, em parte, a atribuição de atividades desvinculadas de qualquer prática voltada à saúde e segurança dos trabalhadores; sendo as mais comuns: atividades administrativas, participação na área de segurança patrimonial, organização de festas de confraternização de fim de ano, execução de tarefas de motorista. Fica claro, portanto, não apenas a distância entre atividade e tarefa, mas, mais do que isso, a divergência e conflitos na definição do próprio objeto de sua atuação.

\section{A fiscalização por órgão estatal}

O acompanhamento de agente fiscal de órgão externo é outra atividade desenvolvida pelo Técnico de Segurança que é fonte de tensão e constrangimento. A fiscalização normalmente é realizada após a ocorrência de adoecimento no trabalho ou acidente grave ou fatal e é realizada principalmente pelos auditores fiscais do Ministério do Trabalho e Emprego, podendo ainda ser efetuada por órgãos do SUS, como Centros de Referência em Saúde do Trabalhador (CEREST) ou Vigilâncias em Saúde do Trabalhador.

No momento em que a empresa está sendo auditada, também ocorre desvio de função do Técnico, entretanto de maneira diferenciada das anteriormente mencionadas, é o chamado "desvio para cima":

TST6: A empresa não está nem aí com nada. Quando chega um auditor fiscal ou alguém do Ministério do Trabalho: "Cadê a documentação? Cadê o Técnico? Chama o Técnico lá! Agora eu quero a documentação. Quero isso, isso, isso". [...] [Diretor da empresa:] "Esse aqui [Técnico], ele é meu vice-presidente!" "Pode usar a sala da Diretoria, usa meu notebook aí”. Daqui a pouco o cara [fiscal] vai embora, se você disse alguma coisa errada: "Para que você falou isso? Tu és louco!”

Durante a fiscalização é percebida mudança da forma de tratamento por interlocutores internos à empresa. O Técnico de Segurança, que até então possuía participação marginal na gestão da saúde e segurança, ganha posição central:

TST1: Agora você quer ver o pessoal lembrar de você? $O$ dia em que, infelizmente, você tem um acidente. Aí, aquelas pessoas que estavam acima de você e que falaram assim: "Não, toca a máquina. Deixa o parafuso quebrar". Some todo mundo. Some. Some. Porque é a hora que você vai ter que evidenciar que você tomou uma postura.

Ainda que a presença do auditor fiscal no interior da empresa cause tensão no ambiente da empresa discussões, trocas de acusação etc. - os participantes manifestaram que a maior fonte de preocupação são os possíveis desdobramentos da fiscalização: processo civil e criminal por falha ou omissão do Técnico, dada sua responsabilidade sobre as condições de trabalho precárias verificadas pelo auditor.

TST1: Quando está ali, no âmbito da empresa, é uma coisa. Quando isso envolve um órgão externo, por exemplo, pode estar a Delegacia. Você tem que parar na frente do delegado e explicar. Ele olha pra você e fala: "Qual é o seu papel na empresa? Por que você não tomou uma atitude? Você não tem autonomia? Por que não-sei-o-quê?"”

Outro motivo de constrangimento durante a fiscalização é o não reconhecimento das condições de trabalho do Técnico de Segurança pelo auditor fiscal. Foi trazido pelos participantes que o olhar do auditor se direciona exclusivamente à linha de produção. Os Técnicos não são, portanto, identificados como trabalhadores. Ao manifestar ao auditor sua condição de impedimento para agir sobre os determinantes do acidente, os Técnicos comumente ouvem réplicas como: "Se está ruim, mude de profissão".

\section{A investigação de acidente de trabalho}

Dessa maneira, as tentativas do Técnico de Segurança de intervir em situações identificadas como prejudiciais à saúde e segurança dos operadores são percebidas pelos demais atores como empecilhos para o bom andamento do processo produtivo.

TST1: Eu tenho um caso aqui de um acidente que eu fui investigar. [...] Eu era novo na empresa, quando eu cheguei às 14h, o RH falou: "Ó, aconteceu um negócio lá na produção, nesse momento, dá para você dar um pulinho lá?” Eu cheguei lá, quando o gerente de produção me viu ele fez assim, literalmente: "O que você quer aqui?" Desse jeito: "O que você quer aqui? O que você veio fazer aqui?" E eu com papel e caneta na mão: "Eu vim a pedido da X, de Recursos Humanos, vim ver o que aconteceu aqui, oferecer uma contribuição que eu possa trazer, uma sugestão pra resolver o problema". [Gerente de produção:] "Não quero ouvir sua opinião e não quero nem saber!" Falei: "Espera aí, você é gerente industrial, seria coerente. Eu vim..." [Gerente de produção:] "Não quero saber o que você pensa, 
o que vai, quem é coerente ou vai deixar de ser coerente. Se vira lá com a $\mathrm{X}$, vai lá e depois eu falo com ela”. Diante disso, o quê você vai fazer? Você vira as costas e vai embora. Inclusive eu fui embora mesmo da empresa. Não dá.

A dubiedade nas atribuições do TST foram inicialmente explicadas como a disparidade entre a política de Estado em saúde e segurança no trabalho e a política interna das empresas. À medida que a discussão se desenrolava, havia verbalizações sobre a coexistência de interesses contrários que se concretizavam nessas práticas.

TST2: Mas o foco da investigação não deve ser apontar responsáveis. Mas é fazer a prevenção. Você elencar tudo que precisa ser feito para corrigir aquela situação, para que ela não se repita. Depende da empresa. [...] Eu estou falando em nível de providências, chega até a nível de diretoria. Agora, o andamento disso vai depender muito daquilo que acontece na empresa. Tem diretor que está se lixando da situação. Largo o relatório na mão dele, é a mesma coisa que nada. Tem outra que não. Pega, bota toda a chefia numa sala e conversa com todo mundo: "Espera aí, vamos tomar uma providência, não é por aí” e tal. Então depende muito de com quem você está mexendo e qual a cultura dele.

Os Técnicos colocaram em diferentes momentos o conflito entre produção e segurança, em outras palavras, a segurança como entrave para os lucros e rendimento da empresa. Ao tratar de alteração recente em legislação, no que tange o uso de tipo específico de maquinário, um dos participantes trouxe depoimento de experiência pontual:

TST7: Eu vou interditar todas as máquinas, porque todas estão fora de uso. São prensas de engate de chaveta e estão totalmente fora de uso. São máquinas de 1976. Agora, aparentemente ele achou melhor comprar prensas novas e jogar essas ${ }^{3}$. Eu fui falar pra ele [empresário] assim: "Olha, a lei determina que nós não podemos jogar. Você não pode repassar isso. Você não pode! Você não pode repassar". Ele falou: "Não esquenta não. Eu vou repassar isso aí, não vai ter problema de nota, não vai ter problema de nada. Eu vou no toma lá dá cá e vai lá pro nordeste, vai lá não sei para onde mas eu vou repassar". Mas eu alertei ele, eu falei: "Olha, não". Mas...

Em outras situações, o foco maior sobre a produtividade é percebido na proximidade do Técnico com o pessoal de chão de fábrica e na observação do processo produtivo, conforme ilustrado abaixo:

TST2: Para você fazer uma peça tem um procedimento de como realizar. Só que se você não realizar esse procedimento da forma que é descrito, você consegue aumentar a produção [...] diminuindo segurança você tem uma produtividade maior.

TST8: Não adianta você querer peitar ninguém porque você não vai conseguir, por mais político que você seja. Por que, infelizmente, a nossa cultura hoje é para o quê? Produção, produção e mais produção. Se o cara estiver lá e encontrar uma situação de risco na área, se não tiver uma pessoa, um contato para chegar e mostrar que realmente a peça [Produção] tem que parar, nem sempre para.

Em tais circunstâncias, sendo a lógica da produção predominante sobre a gestão de segurança, o TST passa a ser percebido como um sujeito que dita regras e cobra comportamentos, de operadores de chão de fábrica, incompatíveis com melhores resultados de produção.

TST1: O Técnico ser visto como dedo-duro, como cagueta, como fofoqueiro, como puxa-saco da empresa.

TST9: Ele é visto como o dedo-duro, né? "P...! Lá vem o dedo-duro. Lá vem aquele sacana. Lá vem o não-sei-o-quê." Eu já vi caso de um funcionário querer agredir um colega meu.

As falas a seguir expressam a preponderância de abordagem da segurança comportamental sobre um entendimento mais global do trabalho, desconsiderandose os aspectos imateriais e subjetivos que o compõe.

TST7: Quando você recruta um empregado, você passa para ele um Termo de Responsabilidade, de obrigações: "Olha, aqui você vai ter isso, você tem que obedecer, você tem essa norma interna da empresa. Na qual você vai ter essas obrigações e responsabilidades". Tudo bem, ele concorda. Quando você entrega os equipamentos e fala: "Olha, você vai ter que seguir". Aí ele se retrai, ele burla, ele não quer usar o equipamento. Então acarreta nas advertências e tudo mais. [...] Muitas vezes até eu falo: "Pô, mas quando você entrou aqui, você não concordou? Não estava sabendo que você teria que usar o protetor, o óculos?”

TST6: Depois que você alertar a pessoa, depois que você conversar com a pessoa, pra que você comece a punir. Mas punir, entendeu? Aí, tem o funcionário. Você não vai usar isso daqui, então eu vou ter..., vamos pedir advertência, levar a situação para o $R H$, para o líder, para liderança dele lá. É punir o camarada, se ele está tomando essa advertência é porque você teve uma conduta.

TST1: Ele [o trabalhador] não tem cultura. Aí você vai ter que domesticar o cara [grifo nosso]. O termo até pesado pra usar, não é conscientizar, é domesticar o cara a exercer uma questão de segurança.

\footnotetext{
3 Foi estabelecido na Convenção Coletiva de Melhoria das Condições de Trabalho em Prensas e Equipamentos Similares, Injetoras de Plástico e Tratamento Galvânico de Superfície nas Indústrias Metalúrgicas do Estado de São Paulo (ASSOCIAÇÃO BRASILEIRA DA INDÚSTRIA DE MÁQUINAS E EQUIPAMENTOS, 2008) o Programa de Prevenção de Riscos em Prensas e Similares (PPRPS), onde está determinado que prensas obsoletas, inadequadas nos termos da nova redação da NR12, não podem ser transferidas, doadas ou vendidas a terceiros.
} 


\section{A produtividade do Técnico de Segurança}

Interessante pontuar a forma como a exigência por produtividade não se aplica apenas aos operadores de linha de produção. Os participantes afirmaram ser comum o estabelecimento de metas de produção para o Técnico de Segurança, por exemplo: quantidade de inspeções por posto de trabalho durante determinado intervalo de tempo; quantidade de materiais educativos produzidos para distribuição durante a Semana Interna de Prevenção de Acidentes de Trabalho (SIPAT). Entretanto, a mensuração da produção individual do Técnico por parte das altas hierarquias da empresa não necessariamente tem por base ações e iniciativas para a prevenção de adoecimento e de acidentes.

TST1: No final do mês tem que apresentar um relatório, pra questão de controle, de tudo o que vocêfez. A pessoa: "Ô, a taxa de acidente está aumentando. Você não é técnico de segurança? A taxa de acidente está aumentando! O que você está fazendo?”

Outro "indicador" da produtividade do Técnico comumente utilizado é o fornecimento de equipamentos de proteção individual (EPI), a partir do acompanhamento de baixa no almoxarifado:

TST3: Até no controle, se estourou um pouquinho no orçamento em $20 \%$ : "Tá dando EPI pra quem?"

\section{A alta rotatividade de profissionais da categoria}

Os participantes percebem entre a categoria uma alta rotatividade de profissionais e atribuem-na a uma forma de expressão das adversidades enfrentadas na realidade de trabalho dos Técnicos.

TST10: Nós somos obrigados, nós estamos aqui [na empresa], nós temos que fazer. Porque se você sai de uma determinada empresa hoje, você vai pra outra, é claro que é a mesma coisa, você vai pra mesma situação. [...] O negócio é segurar. O cara [empresário] fala: "Contratei esse aqui, esse aqui não quer fazer nada, só negócio de segurança. Não quer ficar. Não dá não, o outro [TST] fazia. Pega isso aqui e vai embora. Não passou nem na experiência".

TST4: Se esse técnico falar que vai parar a máquina, ele é trocado. Ele é substituído. Por quê? Ele tem que obedecer o SESMT.

A partir do relato acima depreende-se também a questão do medo do desemprego, preocupação perceptível nos relatos dos participantes. O papel do Técnico dentro da esfera familiar, como provedor do lar, compõe um fator adicional de autocobrança, onde ele se vê obrigado a se submeter às condições de trabalho da forma como se apresentam. Aspecto esse contemplado na fala abaixo:
TST3: Eu tenho uma família. Eu não vou pedir demissão só porque o patrão não quer que eu faça a minha função. Muitas vezes ele não quer que eu faça, tá bom, não vou fazer. Se quer que eu finja que eu trabalho? Então eu vou fingir que eu trabalho. Várias vezes eu me deparo com isso.

A posição do Técnico como intermediário entre a produção e a gerência da empresa gera, no entendimento dos participantes, constrangimento pelo acesso a informações das instâncias decisórias que não podem ser compartilhadas com o setor operacional.

\begin{abstract}
TST1: O Técnico, ele exerce o papel de fazer o contato entre o operacional e a chefia deles. Então, ele participa junto com a chefia, ele sabe exatamente qual é a linha que a chefia está adotando, ou que vai adotar, e ao mesmo tempo ele está ali, junto com a galera, ele sabe os pontos positivos e negativos. Ele não pode levar tudo o que ele sabe lá para cima e não pode pegar tudo o que ele sabe lá de cima e trazer aqui para baixo. Então, ele fica fazendo um filtro. Pode ser que você esteja aqui agora, mas amanhã você não vai estar aqui. Mas eu tenho que levar você numa condição que você possa imaginar que vai estar aqui mais dois [anos], mas você não vai estar aqui nem mais duas horas.
\end{abstract}

\section{O trabalho e o sofrimento dos Técnicos de Segurança}

Ao tratarem dos reflexos do exercício profissional na vida pessoal, os TST comentaram que seu trabalho afeta momentos de descanso e lazer:

TST9: Isso foi o que mais acabou comigo, o fator psicológico. De tanta preocupação. Eu saio de casa, eu não paro de pensar nos caras que tão lá trabalhando, [...] de ser prejudicado futuramente numa fiscalização ou por um acidente que venha a causar uma morte dentro da empresa.

Os impactos sobre a saúde são percebidos de diferentes maneiras pelos Técnicos. Abaixo, um Técnico comenta o desenvolvimento de sintomas orgânicos em decorrência do trabalho:

TST8: Eu trabalhei numa empresa muitos anos. Trabalhei em RH e depois passei [para a] Segurança. Foi feito todo um trabalho, a empresa começou a viver um nível de tensão tão forte em cima da segurança e começou toda uma pressão em cima da gente. [...] Eu tinha todos os sintomas de Diabetes. Eu cheguei muitas vezes a ir pra enfermaria com a pressão lá embaixo. O Médico do Trabalho virava e falava pra mim: "Sai daqui, vai dar palestra, vai descansar. Isso aqui está um inferno". O próprio Médico do Trabalho. [...] Então, você vai insistindo. Você vai cada vez passando mal. Mal mesmo. Cheguei a uma época a pedir demissão. Não deixavam. Estava em vias de auditorias e tal, [...] Eu saí dessa empresa. Fui trabalhar numa outra empresa. [...] Uma empresa que tinha vontade de mudar. A gente conseguiu fazer um trabalho. Fiquei dez anos e meio lá. Nunca, depois que eu saí dessa primeira empresa, nunca mais eu sinto dores nas pernas, nunca mais eu tive 
nenhum sintoma de Diabetes, faço o exame até hoje [...] Era a questão de stress mesmo. Nessa outra empresa que eu fui, peguei um clima muito pior em termos de funcionários, em termos de equipamentos, mudaram os equipamentos, deram recurso para que a gente treinasse o pessoal, mudasse o comportamento das pessoas, deu abertura para isso. Conseguimos fazer um bom trabalho, a coisa mudou e a minha saúde perfeita. E eu fui ficando cada vez mais velho.

Os participantes constataram ainda o adoecimento como consequência do sofrimento mental. Na fala a seguir, comenta-se a respeito do desenvolvimento de alcoolismo:

TST1: É muito comum camarada ficar lá esmagado o tempo todo. O colega cair até no vício de bebida por frustração de não poder desempenhar o trabalho bem desempenhado. Tenho visto aí cair no alcoolismo.

O trabalho de Técnico de Segurança, ainda que permeado por fatores negativos para a saúde mental, também possui elementos positivos identificados pelos participantes. Foram mencionados momentos agradáveis, de conquistas e realizações, à parte as dificuldades e limitações enfrentadas:

TST9: Eu não consegui meu objetivo, mas eu fiz alguma coisa, por menor que seja, para evitar que um colega meu de trabalho, pai de família, saia de dentro da empresa mutilado, cego, faltando uma perna, qualquer situação que venha a constranger ele e a família dele para o resto de sua vida. É muito gratificante poder fazer isso daí.

TST11: Quando você vê que tudo aquilo que você muitas vezes brigou, conversou com as pessoas, mostrou a necessidade, está sendo realmente implantado. Quando você vê que no seu trabalho você começa a colher os frutos. Sempre vai ver [resultados]. Depende muito. Mas é um processo contínuo. Uma cultura de 43 anos você não muda em um, dois anos. É um trabalho de formiguinha.

Conforme apresentado anteriormente, o trabalho dos Técnicos de Segurança é composto por uma diversidade de atividades a serem realizadas em meio a limitações, conflitos, contradições e impedimentos de diferentes ordens.

\section{Discussão}

A partir das falas dos participantes durante os grupos de Análise Coletiva do Trabalho, pode-se perceber a existência de dois "níveis" de tarefa para os Técnicos de Segurança do Trabalho: as atribuições constantes em legislação - política de saúde e segurança do trabalho, principalmente, a Norma Regulamentadora 4, do Ministério do Trabalho e Emprego (BRASIL, 1978, 1987) - e as determinações da empresa metalúrgica contratante. Ao TST é delegado um universo de atribuições, entretanto a categoria possui margem de ação reduzida para o seu cumprimento. A distância entre a atividade e a tarefa do Técnico pode ser entendida por diversos prismas.

Primeiramente existe a questão da origem dos SESMT. Peeters et al. (2003) e Assunção e Lima (2003) apontam a composição e manutenção do Serviço unicamente com a finalidade de dar resposta a uma obrigatoriedade legal. Sendo assim, o distanciamento da postura prevencionista antecederia a constituição concreta do próprio Serviço. A esse respeito, Lacaz (1996) aponta que alguns dos profissionais do SESMT (Médico e Enfermeiro do Trabalho) são o veículo operacional para a realização dos exames admissionais e periódicos. Sua atuação se limitaria, portanto, ao gerenciamento desses exames.

No entendimento dos TST, as dificuldades e limitações encontradas em seu cotidiano de trabalho advêm principalmente da coexistência de lógicas antagônicas no interior das empresas: a segurança e a produção, estando na figura do TST o ponto de conflito entre ambas. Nesse sentido, o profissional é visto como fonte de distúrbio, por constantemente trazer às instâncias decisórias da empresa os problemas e riscos identificados no trabalho em linha de produção, além de buscar intervir sobre o processo produtivo para implantar modificações e alterações, prejudicando assim a produtividade. A insuficiência de infraestrutura e recursos materiais, o desvio de atribuição e o estabelecimento de metas de produção a partir de indicadores sem qualquer relação com a atividade desenvolvida são, na percepção dos TST, a expressão da forma como a categoria é vista nas empresas: um agente limitador da produção.

Outra contradição encontrada ao se analisar o trabalho dos Técnicos de Segurança diz respeito à coexistência de abordagens contrárias, que dão suporte a entendimentos heterogêneos sobre o trabalho e quanto ao contexto em que é realizado. A saber: abordagens fundamentadas nas ciências físicas em oposição às ciências humanas (DANIELLOU, 1996). Ou, como discriminam Garrigou et al. (1999): a compreensão da segurança comportamental versus a visão centrada no homem. Na visão da segurança comportamental há direcionamento do olhar do especialista ao conteúdo visível e mensurável do que é executado pelo operador; o trabalho constituir-se-ia da sobreposição de tarefas simples e da somatória de suas partes.

O papel do Técnico, nessa abordagem, é o de vigiar o cumprimento estrito de normas e punir os trabalhadores faltosos, vistos como os principais responsáveis e culpados pelas próprias ocorrências lesivas. A predominância da segurança comportamental fica bem expressa na verbalização do Técnico, ao comentar que lhe cabe "domesticar" o trabalhador. 
Entre suas consequências imediatas, ela afasta e isola o Técnico dos trabalhadores, justamente os principais interessados e potenciais aliados do Serviço.

A preponderância da visão da segurança comportamental, com o maior direcionamento da atenção dos profissionais de segurança ao conteúdo visível do trabalho e aos riscos físicos presentes no ambiente, é criticada por diversos autores (VALVERDE, 2010; VILELA, 2003, 2010; CAMBRAIA; FORMOSO; SAURIN, 2008; ALMEIDA; JACKSON FILHO, 2007; FONSECA; LIMA, 2007; VILELA; MENDES; GONÇALVES, 2007; VILELA; IGUTI; ALMEIDA, 2004; ASSUNÇÃO; LIMA, 2003; ALMEIDA, 2001; DWYER, 1994). O aspecto organizacional (divisão do trabalho entre os operadores, pressões temporais) é desconsiderado, bem como o conteúdo subjetivo das atividades (conflito entre as normatizações e a produção, processos mentais; a finitude da capacidade de o trabalhador adaptar suas funções psicológicas e fisiológicas às exigências da atividade). Pensando no trabalho dos Técnicos de Segurança em chão de fábrica, esse tipo de entendimento impede a percepção justamente dos fatores desencadeantes de sofrimento e adoecimento dos trabalhadores, o que contribui para um alcance limitado de suas intervenções e a inviabilização de seu possível papel como interlocutor válido para a compreensão e a transformação dos processos de trabalho e dos riscos.

A forma como o serviço de saúde ocupacional está organizado contribui para sua funcionalidade, no sentido de que as necessidades de saúde e segurança dos trabalhadores tenham o encaminhamento adequado (ELGSTRAND, 2009). No entanto, os conceitos de risco e de acidente partilhados pela equipe do SESMT e gestores da empresa têm papel determinante na proteção à saúde dos trabalhadores. A concepção reducionista entende os riscos como sendo fatores isolados do trabalho e tem sua base em modelo tradicional de estudo de agentes físicos, químicos ou biológicos presentes no ambiente. É fortemente ligada às disciplinas clássicas, como a Medicina do Trabalho e a Saúde Ocupacional. Nessa abordagem caberia aos profissionais do SESMT identificar e controlar fatores de risco pontuais, especialmente os visíveis, gerenciar o fornecimento de EPIs, controlar o comportamento errôneo dos trabalhadores no sentido de seu disciplinamento. O conteúdo do trabalho, sua complexidade, diferenças qualitativas, relações entre seus elementos e a articulação entre etapas diferentes do processo de trabalho permanecem à margem desse tipo de análise (LAUREL; NORIEGA, 1989).

A visão do especialista que sabe e que deve impor, "adestrar" e disciplinar os trabalhadores "incultos", condizente com a visão hierárquica da fábrica taylorista, desconsidera o papel central do trabalhador enquanto regulador das variabilidades e o principal agente de segurança (LLORY, 1999). Para De La Garza e Fadier (2007) a participação do trabalhador é fundamental para o sucesso do processo de produção. O êxito do sistema e seu funcionamento de modo seguro e eficaz passam justamente pelo distanciamento das prescrições. Ao se afastar do que lhe é predeterminado, o trabalhador utiliza suas competências e sua experiência acumulada e consegue prever situações e corrigir desvios percebidos. Nesse sentido, Assunção e Lima (2003) comentam ser na rigidez da organização do trabalho, em outras palavras, na redução da margem de ação do trabalhador, que se encontra a gênese da nocividade do trabalho.

Depreende-se pela fala dos participantes uma semelhança entre o olhar do Técnico, como especialista que sabe da segurança, e das hierarquias superiores da empresa sobre a atividade do operador. Interessante pontuar que, ao comentarem sobre sua própria realidade de trabalho, em especial no que tange às cobranças e ao estabelecimento de metas de produção, os participantes teceram críticas a sua chefia e a alta hierarquia das empresas pela inobservância dos aspectos imateriais da atividade do Técnico de Segurança. Portanto, contraditoriamente, coexistem a crítica à invisibilidade de seu trabalho e a adesão à visão da segurança comportamental. O Técnico é vítima e algoz da mesma abordagem de que é portador: o trabalho é visto fora do contexto global da produção e o trabalhador é pressionado a atingir resultados inviáveis, dados os meios e possibilidades reais de ação que possui.

Outra forma de expressão desse paradoxo é a maneira como o papel do Técnico de Segurança é visto dentro da empresa. Peeters et al. (2003), Assunção e Lima (2003) e Garrigou et al. (1999) comentam que a visão preponderante da segurança comportamental reduz o papel desses profissionais a vigilantes do comportamento dos operadores dentro das empresas, o que retroalimenta, portanto, a percepção dos operadores em relação ao TST como "cagueta". Quando realizada com essa finalidade, a vigilância verifica apenas aspectos secundários e superficiais, mas não intervém nos determinantes organizacionais dos riscos, ou seja, aos Técnicos é permitido apenas "colocar curativos em uma perna de madeira".

Independentemente do que é determinado ao Técnico realizar, as cobranças quanto às iniciativas para melhoria das condições de trabalho dos operadores permanecem. A exigência se concretiza diferentemente, partindo do ambiente interno, mas

\footnotetext{
4 Expressão utilizada por M. Llory (2012) em conferência, ao se referir às recomendações fruto de investigações superficiais de acidentes industriais.
} 
também de órgãos de Estado. Internamente, em nível hierárquico superior, é a empresa, por exemplo, que pode cobrar e responsabilizar o Técnico pela redução dos índices de acidente de trabalho, enquanto que, em níveis inferiores, os operadores do setor de produção também reivindicam resultados preventivos. Pensando em órgãos públicos, o Técnico de Segurança é chamado à responsabilidade como profissional da área de saúde e segurança pelos auditores fiscais do Ministério do Trabalho e Emprego, pelos profissionais de vigilância do SUS ou pelos peritos ou policiais que investigam algum acidente grave ou fatal.

Em diferentes momentos, durante os grupos, os participantes comentavam a "falta de autonomia" do Técnico de Segurança. Clot $(2007,2010)$ cunhou a expressão "poder de agir", que acreditamos ser a mais adequada, dado o universo de entendimentos possíveis para "autonomia”. O "poder de agir" diz respeito ao que é permitido e possível ao trabalhador verdadeiramente realizar dentro de seu trabalho habitual. Para o autor, esse conjunto de ações é heterogêneo e mutável, podendo se ampliar ou reduzir.

No entendimento de Clot, as causas do adoecimento mental no trabalho residem no que é impedido ao trabalhador realizar e não no conteúdo da atividade efetuada. Pois, ainda que lhe seja permitido desempenhar uma pluralidade de ações e que ele o faça com sucesso, em a atividade sendo esvaziada de sentido, seus desdobramentos serão sempre insatisfatórios aos olhos do trabalhador. O "sentido" da atividade diz respeito ao que o sujeito percebe como importante e o objetivo e resultados possíveis através de determinada ação. A situação de conflito que o trabalhador vivencia ao não encontrar eco para as suas expectativas dentro do trabalho que realiza - poder de agir atrofiado - causa sofrimento intenso e pode conduzir à impossibilidade de continuação da ação por a atividade se tornar psicologicamente inviável (CLOT, 2010).

Assunção e Lima (2003) comentam sobre o movimento natural do trabalhador de se ajustar às exigências do trabalho, utilizando recursos pessoais de ordem física, cognitiva, temporal e material para dar cumprimento ao que lhe é determinado. Entretanto, à medida que as demandas excedem as possibilidades individuais de que dispõe, tem-se por consequência reflexos negativos sobre a sua saúde. A organização do trabalho do Técnico, da forma como se apresenta, traz sofrimento mental intenso, expresso pelos Técnicos de variadas formas: "frustração", "sensação de ser inútil”, "ficar feito um bobão".

Refletindo sobre o trabalho dos Técnicos, ficam claros os elementos que Clot comenta comporem a chamada "mistura explosiva" (CLOT, 2010, p. 11): atividade expropriada de sentido e sentimentos de insignificância; ambos fortemente trazidos pelos participantes ao longo dos grupos. Entretanto, o mesmo autor também afirma situações de superação, onde o sujeito reconhece elementos realizáveis dentro de raio de ação. Em tais circunstâncias o indivíduo se torna psicologicamente mais disponível. A atividade então se renova de sentido a partir de um resultado positivo inesperado, que ultrapassa os objetivos da demanda e pode, inclusive, transpor as expectativas do próprio sujeito (CLOT, 2010). Quando os participantes comentam sobre elementos que os motivam e proporcionam satisfação no trabalho observa-se a perspectiva de mudança na organização do trabalho. Ao obter êxito através de seu exercício profissional e/ ou lançando mão de estratégias diversas no sentido de interferir positivamente sobre as condições de trabalho constatadas, observa-se a ampliação do poder de adir dos Técnicos.

O fluxo de informações partindo dos Técnicos para as instâncias decisórias da empresa também é um fator dificultador presente no dia a dia dos TST. O Técnico identifica situações de risco à saúde dos operadores, mas se percebe impedido para efetuar as mudanças necessárias. Llory (1999), ao tratar sobre sistemas complexos, comenta o rótulo de "transmissor de más notícias” atribuído aos profissionais da prevenção pela alta hierarquia da empresa, dado que constantemente trazem as disfunções presentes no sistema, riscos, necessidade de intervenções dispendiosas etc. A comunicação deficitária, além de limitar ações preventivas, implica sobre as relações sociais de trabalho dos Técnicos, dado que a direção da empresa, ao taxá-los dessa maneira, legitima tal rótulo dentro do meio ambiente de trabalho.

A partir do discurso dos participantes apreendese que, a despeito de exercer função essencial na prevenção, não há nos contratos de trabalho ou negociações coletivas medidas de proteção contra a despedida desmotivada. Cabe destaque também à rotatividade e fragilidade de seu contrato de trabalho, contrato comum regido pela Consolidação de Leis do Trabalho (CLT), por sua vez caracterizado como um contrato individual de trabalho, que mesmo regulado e protegido minimamente pelo Estado, permanece ainda um contrato unilateral, onde impera livre a vontade do empregador (FARIA, 1993; NASCIMENTO, 1991). Foram mencionados a alta rotatividade de emprego na categoria e sentimentos negativos relacionados ao medo do desemprego, constatados por todos. Tal situação fragiliza sobremaneira a autonomia e continuidade de ações de prevenção desses profissionais, havendo constrangimento profissional e também pessoal - por serem chefes de família - para aceitarem as condições de trabalho da forma como se apresentem. Pensando a esse respeito, seria interessante a mudança no vínculo empregatício dos profissionais de saúde e segurança do trabalho, dado que, da forma corrente, a atitude dos 
profissionais os coloca em conflito social com a empresa (GUÉRIN et al., 2001), confronto no qual as objetivos privados (interesses das empresas) se sobrepõem ao benefício da coletividade. À semelhança do que se observa em outros países, o duplo vínculo - Estado e empresa - ou um vínculo protegido contra a dispensa imotivada, permitiria a ampliação da margem de ação desses profissionais em benefício da prevenção.

Ao debaterem a respeito de elementos que contribuem positivamente ao bom desempenho de sua função, os participantes remetem à dimensão individual, atribuindo resultados positivos como decorrentes de características pessoais como persistência e "jogo de cintura": "A pessoa tem que ter uma perseverança muito grande", "Tem que tomar banho de vaselina todo dia”. Peeters et al. (2003) também encontraram entre profissionais de SST, brasileiros e franceses, definições referentes a atributos intraindividuais, tidas como de grande importância para um desempenho de sucesso.

Interessante notar que o estabelecimento de metas de produtividade é mais comumente observado como parte integrante do universo de trabalho do operador de linha de produção. Em literatura, como bem discutem Assunção e Lima (2003), tentativas de aliar condições satisfatórias de trabalho e alta produtividade acabam privilegiando o segundo aspecto em detrimento do primeiro.

Os sentimentos de medo e autoculpabilização decorrem em especial quando da ocorrência de acidentes de trabalho com operadores. Tanto pela sensação de impotência para intervenção nas condições de trabalho precárias dos operadores como pela responsabilidade que recai sobre o TST no caso de AT grave ou fatal. Dentro dessa problemática, o TST é substancialmente limitado para intervir sobre os processos produtivos no sentido da melhoria das condições de trabalho no chão de fábrica.

Quanto à metodologia aplicada, a Análise Coletiva do Trabalho se mostrou uma técnica bastante válida para se conhecer o trabalho da categoria pesquisada. Em se tratando de uma categoria profissional com vínculo com o setor privado, consideramos importante o fato de a ACT preconizar a minimização da possibilidade de identificação dos participantes pelas empresas contratantes, com o intuito de evitar o constrangimento dos trabalhadores. Algumas medidas são adotadas nesse sentido, como a participação voluntária, garantia de anonimato e escolha de ambiente para a realização dos grupos externos ao do trabalho; oferecendo segurança aos participantes, contribuindo para o estabelecimento de confiança entre pesquisadores e sujeitos e favorecendo uma interlocução aberta. Em especial, dado que, conforme foi apresentado, a alta rotatividade de profissionais é uma característica que se faz presente na realidade da categoria.
Outro aspecto é a importância dada à fluidez da discussão entre os participantes, sem o estabelecimento de um roteiro fechado e com o mínimo de interferência dos pesquisadores. Nesse sentido, ainda que a técnica não tenha em absoluto caráter terapêutico, acreditamos ser interessante que os pesquisadores tenham experiência prévia em condução de grupos. Tal conhecimento prático facilita na coordenação dos grupos tanto no aspecto mais concreto - na administração do tempo de duração, por exemplo -,como na identificação de situações em que se faz necessário um redirecionamento da discussão.

Este estudo apresentou algumas limitações. Os participantes do estudo tinham atuado em empresas de diversos ramos econômicos e mencionaram que os problemas e dificuldades enfrentados são semelhantes em todas as empresas. Ainda assim, para generalizar os achados do presente estudo seria necessária a realização de outros grupos de ACT, com Técnicos exercendo sua função em outras áreas, além da metalúrgica. Com relação à técnica utilizada, os grupos foram realizados após evento direcionado aos profissionais de saúde e segurança do trabalho. Tal estratégia se deveu à preocupação de preservar a identidade dos participantes. No entanto, tivemos poucos Técnicos voluntários. Uma maior adesão enriqueceria as discussões e, talvez, possibilitaria aprofundamento em alguns tópicos interessantes, como por exemplo, a questão da drogadição, trazida em um dos grupos.

\section{Considerações finais}

A partir do presente estudo foi possível conhecer o conteúdo material e imaterial do trabalho cotidiano dos Técnicos de Segurança e as percepções desses profissionais a respeito de seu exercício profissional. Dentre os profissionais de saúde e segurança, a categoria possui obrigatoriamente carga horária mais extensa 40 horas semanais - o que, somado às atribuições da categoria, possibilita contato mais próximo com a linha de produção e os operadores quando em comparação com os demais membros do SESMT. Entretanto, ainda que tenha uma função técnica, é subordinado ao coordenador do SESMT em empresas de grande porte, cargo ocupado pelo Engenheiro ou Médico do Trabalho, ou responde diretamente ao proprietário, no caso de empresas menores. $\mathrm{O}$ fato de não possuir poder decisório foi mencionado pelos Técnicos como um elemento limitante da prática profissional. A despeito de ter seu vínculo com uma organização produtiva particular, os Técnicos de Segurança do Trabalho realizam uma atividade de caráter público, tendo por finalidade maior a saúde de uma coletividade composta não apenas por trabalhadores da empresa 
contratante, pois um acidente ocorrido em uma empresa metalúrgica pode ter grande impacto sobre a população de toda uma localidade, não se limitando portanto ao ambiente físico da empresa.

O desvio de função do Técnico de Segurança é algo corrente nas empresas, tendo sido trazido por quase que a totalidade dos participantes. Outro aspecto trazido foi a inserção do Técnico na empresa por determinação legal e não por uma autêntica política preventiva por parte dessas corporações. A prioridade dada à obtenção de lucros e resultados econômicos muitas vezes ocorre em detrimento dos aspectos de saúde, segurança e meio ambiente. Nesse sentido, a atuação preventiva implica na gestão contínua de conflitos tanto com trabalhadores como com gestores, sendo o Técnico visto como um elemento que restringe a produção.

A partir dessas percepções trazidas pelos Técnicos é possível concluir que a categoria tem inserção frágil na política de segurança das empresas e que seu cotidiano de trabalho é fortemente marcado por um "poder de agir" limitado ou mesmo impedido. Na visão dos Técnicos, tal margem de ação limitada é causa de sofrimento para os profissionais da categoria. A natureza do trabalho de prevenção, por suas características conflituosas, somada à vivência constante de sentimentos de ansiedade e insatisfação, pode acarretar em adoecimento psíquico.

A segurança e saúde dos trabalhadores como campo de atuação não se restringe ao ambiente interno das empresas. Ainda que o Técnico de Segurança do Trabalho seja um agente com importância singular nos ambientes de trabalho, profissionais de órgãos públicos compartilham o mesmo objetivo; não apenas auditores fiscais do Ministério do Trabalho e Emprego, mas também profissionais da área da saúde como, por exemplo, os dos Centros de Referência em Saúde do Trabalhador. Dessa maneira, uma maior aproximação e aliança entre profissionais dos SESMT e os agentes públicos da área de saúde e segurança contribuiria para a ampliação do "poder de agir" de todos, no sentido da melhoria das condições de trabalho nas empresas.

\section{Contribuições de autoria}

Inoue, K. S. Y.: delineamento do projeto, levantamento e análise de dados, elaboração do manuscrito. Vilela, R. A. G.: delineamento do projeto, revisão crítica da versão enviada para publicação.

\section{Referências}

ALMEIDA, I. M. Construindo a culpa e evitando a prevenção: Caminhos da investigação de acidentes do trabalho em empresas de município de porte médio. Botucatu, São Paulo, 1997. 2001. 243 f. Tese (Doutorado em Saúde Ambiental)-Faculdade de Saúde Pública, Universidade de São Paulo, São Paulo, 2001.

ALMEIDA, I. M.; JACKSON FILHO, J. M. Acidentes e sua prevenção. Revista Brasileira de Saúde Ocupacional, v. 32, n. 115, p. 7-18, 2007. http://dx.doi. org/10.1590/S0303-76572007000100002.

ASSOCIAÇÃO BRASILEIRA DA INDÚSTRIA DE MÁQUINAS E EQUIPAMENTOS - ABIMAQ. Convenção coletiva de melhoria das condições de trabalho em prensas e equipamentos similares, injetoras de plástico e tratamento galvânico de superfícies nas indústrias metalúrgicas do Estado de São Paulo - 2008/2010. 2008. Disponível em: <http://www.abimaq.org.br/convencoes/2008/CCT_ Prensas_2008.pdf $>$. Acesso em: 5 jun. 2012.

ASSUNÇÃO, A. A.; LIMA, F. P. A. A contribuição da ergonomia para a identificação, redução e eliminação da nocividade do trabalho. In: MENDES, R. Patologia do trabalho. Rio de Janeiro: Atheneu, 2003. p. 17681789.

BRASIL. Decreto-Lei nº 5.452, de 1ํo de maio de 1943. Aprova a Consolidação das Leis do trabalho. Diário Oficial [da] República Federativa do Brasil, Brasília, DF, 9 ago. 1943. Disponível em: <http://www.planalto. gov.br/ccivil_03/decreto-lei/del5452.htm>. Acesso em: 5 nov. 2014.

BRASIL. Ministério do Trabalho e Emprego. Secretaria de Inspeção do Trabalho. Portaria no 3.214 , de 8 de junho de 1978. Aprova as Normas Regulamentadoras - NR - do Capítulo V, Título II, da Consolidação das Leis do Trabalho relativas à Segurança e Medicina do Trabalho. Diário Oficial [da] República Federativa do Brasil, Brasília, DF, 6 jul. 1978. Suplemento.

BRASIL. Ministério do Trabalho e Emprego. Secretaria de Segurança e Medicina do Trabalho. Portaria $\mathrm{n}^{\circ}$ 33, de 27 de outubro de 1983. Altera o Capítulo V, Título II, da Consolidação das Leis do T rabalho relativas à Segurança e Medicina do Trabalho. Diário Oficial [da] República Federativa do Brasil, Brasília, DF, 31 out. 1983. p. 18338-183349. 
BRASIL. Lei no 7.410, de 27 de novembro de 1985. Dispõe sobre a Especialização de Engenheiros e Arquitetos em Engenharia de Segurança do Trabalho, a Profissão de Técnico de Segurança do Trabalho, e dá outras providências. Diário Oficial [da] República Federativa do Brasil, Brasília, DF, 28 nov. 1985. p. 17421.

BRASIL. Decreto no 92.530, de 9 de abril de 1986. Regulamenta a Lei $\mathrm{n}^{\circ} \mathbf{7}$ 7.410, de 27 de novembro de 1985, que dispõe sobre a especialização de Engenheiros e Arquitetos em Engenharia de Segurança do trabalho, a profissão de Técnico de Segurança do Trabalho e dá outras providências. Diário Oficial [da] República Federativa do Brasil, Brasília, DF, 10 abr. 1986. p. 5168.

BRASIL. Ministério do Trabalho e Emprego. Secretaria de Segurança e Medicina do Trabalho. Portaria $\mathrm{n}^{o}$ 34, de 11 de dezembro de 1987. Altera o Capítulo V, Título II, da Consolidação das Leis do Trabalho relativas à Segurança e Medicina do Trabalho. Diário Oficial [da] República Federativa do Brasil, Brasília, DF, 16 dez. 1987. p. 21797-21798.

BRASIL. Ministério do Trabalho e Emprego. Gabinete do Ministro. Portaria $\mathrm{n}^{\circ} \mathrm{3} .275$, de 21 de setembro de 1989. Define as atividades do Técnico de Segurança do Trabalho. Diário Oficial [da] República Federativa do Brasil, Brasília, DF, 22 set. 1989. p. 16966-16967.

BRASIL. Ministério do Trabalho e Emprego. Gabinete do Ministro. Portaria no 262, de 29 de maio de 2008. Regulamenta o exercício da profissão do Técnico de Segurança do Trabalho. Diário Oficial [da] República Federativa do Brasil, Brasília, DF, 30 maio 2008. p. 118.

BRASIL. Ministério do Trabalho e Emprego. Secretaria de Inspeção do Trabalho. Portaria no 197, de 17 de dezembro de 2010. Altera a Norma Regulamentadora nº 12 - Máquinas e Equipamentos. Diário Oficial [da] República Federativa do Brasil, Brasília, DF, 24 dez. 2010. p. 211-232.

CAMBRAIA, F. B.; FORMOSO, C. T.; SAURIN, T. A. Diretrizes para identificação, análise e disseminação de informações sobre quase-acidentes em canteiros de obras. Ambiente Construído, Porto Alegre, v. 8, n. 3, p. 51-62, 2008.

CAVALHEIRO, M. E. et al. Análise da medicina e segurança do trabalho: estudo de caso Projetados Finger. In: SIMPÓSIO DE EXCELÊNCIA EM GESTÃO E TECNOLOGIA, 8., 2011, Resende. Anais... Resende: Associação Educacional Dom Bosco, 2011. p. 1-14.

CLOT, Y. A função psicológica do trabalho. 2. ed. Petrópolis: Vozes, 2007.

CLOT, Y. Trabalho e poder de agir. Belo Horizonte: Fabrefactum, 2010.

DANIELLOU, F. A prevenção de acidentes começa na concepção da organização do trabalho. In:
SPERANDIO, J. C. L'Ergonomie face aux changements technologiques et organisationnels du travail humain. Tolousse: Octares Editions, 1996. p. 430-431.

DE LA GARZA, C.; FADIER, E. Segurança e prevenção: referências jurídicas e ergonômicas. In: FALZON, P. (Ed.). Ergonomia. São Paulo: Blucher, 2007. p. 125139.

DWYER, T. Uma concepção sociológica dos acidentes de trabalho. Revista Brasileira de Saúde Ocupacional, São Paulo, v. 81, n. 22, p. 15-19, 1994.

ELGSTRAND, K. Occupational health services. In: ELGSTRAND, K.; PETERSSON, N. F. (Ed.). Occupational safety and health of development. Stockholm: Royal Institute of Technology, 2009. p. 623-631.

FARIA, C. Contrato coletivo: vontade coletiva ou imposição? Conjuntura, São Paulo, n. 54, p. 1-14, 1993.

FEDERAÇÃO NACIONAL DOS TÉCNICOS DE SEGURANÇA DO TRABALHO - FENATEST. Empregabilidade Brasil. 2012. Disponível em: <http:// www.fenatest.org.br/empregabilidade-brasil.php $>$. Acesso em: 26 maio 2012.

FERREIRA, L. L. Análise coletiva do trabalho. Revista Brasileira de Saúde Ocupacional, São Paulo, v. 21, n. 78, p. 7-19, 1993.

FERREIRA, L. L. Escravos de Jó, KABAN e L.E.R. Production, São Paulo, v. 8, n. 2, p. 151-167, 1998.

FERREIRA, L. L. Psychodynamique du travail et analyse collective du travail. Travailler, v. 25, n. 1, p. 97-107, 2011. http://dx.doi.org/10.3917/trav.025.0097.

FONSECA, E. D.; LIMA, F. P. A. Novas tecnologias construtivas e acidentes na construção civil: o caso da introdução de um novo sistema de escoramento de formas de laje. Revista Brasileira de Saúde Ocupacional, São Paulo, v. 115, n. 32, p. 53-67, 2007.

GARRIGOU, A. et al. As atividades dos profissionais de segurança: uma problemática desconhecida. In: CONGRESSO BRASILEIRO DE ERGONOMIA (ABERGO), 9., 1999, Salvador. Anais... Salvador: Fundação Luís Eduardo Magalhães, 1999. 1 CD-ROM.

GUÉRIN, F. et al. A construção da ação ergonômica. In: _. Compreender o trabalho para transformálo. São Paulo: Bluncher:Fundação Vanzolini, 2001. p. 85-99.

LACAZ, F. A. C. Saúde do trabalhador: um estudo sobre as formações discursivas da academia, dos serviços e do movimento sindical. 1996. $432 \mathrm{f}$. Tese (Doutorado em Ciências Médicas)-Faculdade de Ciências Médicas, Universidade Estadual de Campinas, Campinas, 1996. 
LAUREL, A. S.; NORIEGA, M. Processo de produção e saúde: trabalho e desgaste operário. São Paulo: Hucitec, 1989.

LLORY, M. Silêncio dos executivos, pressões das organizações. In: _. Acidentes industriais: o custo do silêncio. Rio de Janeiro: Multimais, 1999. p. 285306.

LLORY, M. A importância fundamental da metodologia. A abordagem clínica das organizações. In: ENCONTRO PRESENCIAL DO FÓRUM DE ACIDENTES DE TRABALHO, 30., 2012, São Paulo. São Paulo: Fundacentro, 2012.

NASCIMENTO, A. M. Direito sindical de acordo com a Constituição Federal e com a nova lei de greve. 2. ed. São Paulo: Saraiva, 1991.

PEETERS, S. E. et al. Segurança do Trabalho: que trabalho é esse? In: ENCONTRO NACIONAL DE ENGENHARIA DE PRODUÇÃO (ENEGEP), 23., 2003, Ouro Preto. Anais... Ouro Preto: Universidade Federal de Ouro Preto, 2003. p. 1-8.

SALAZAR, M. K. et al. Occupational health services at ten U.S. Department of Energy weapons sites. American Journal of Industrial Medicine, v. 43, n. 4, p. 418-428, 2003. http://dx.doi.org/10.1002/ajim.10196. PMid:12645097

TAKARO, T. K. et al. Barriers and solutions in implementing occupational health and safety services at a large nuclear weapons facility. Journal for Healthcare Quality, v. 22, n. 6, p. 29-37, 2000. http://dx.doi.org/10.1111/j.1945-1474.2000.tb00163.x. PMid:11186038

VALVERDE, C. Para uma contextualização da prevenção em segurança e saúde ocupacional no sector da construção: contributos da formação de coordenadores de segurança e saúde. Laboreal, Porto, v. 6, n. 2, p. 47-51, 2010. Disponível em: <http:// laboreal.up.pt/files/articles/2010_12/pt/47-51f.pdf $>$. Acesso em: 20 jul. 2012.

VAN DER DRIFT, D. W. Towards an effective cooperation between companies and occupational safety and health services. International Journal of Occupational Medicine and Environmental Health, v. 15, n. 2, p. 179-183, 2002. PMid:12216776

VILELA, R. A. G. Teoria da culpa: a conveniência de um modelo para perpetuar a impunidade na investigação das causas dos acidentes de trabalho. In: ENCONTRO NACIONAL DE ENGENHARIA DE PRODUÇÃO (ENEGEP), 23., 2003, Ouro Preto. Anais.... Ouro Preto: ABREPO, 2003. p. 1-8.

VILELA, R. A. G.; IGUTI, A. M.; ALMEIDA, I. M. Culpa da vítima: um modelo para perpetuar a impunidade nos acidentes do trabalho. Cadernos de Saude Publica, v. 20, n. 2, p. 570-579, 2004. http:// dx.doi.org/10.1590/S0102-311X2004000200026. PMid:15073638

VILELA, R. A. G.; MENDES, R. W. B.; GONÇALVES, C. A. H. Acidente do trabalho investigado pelo CEREST Piracicaba: confrontando a abordagem tradicional da segurança do trabalho. Revista Brasileira de Saúde Ocupacional, v. 32, n. 115, p. 29-40, 2007. http:// dx.doi.org/10.1590/S0303-76572007000100004.

VILELA, R. A. G. Da vigilância para a prevenção: Contribuição da Ergonomia da Atividade no aprimoramento do Sistema de Vigilância de Acidentes de Trabalho (SIVAT), Piracicaba. 2010. 138 f. Tese (Livre Docência em Saúde Ambiental)-Faculdade de Saúde Pública, Universidade de São Paulo, São Paulo, 2010. 